\title{
Recycling and Disposal Methods for Polyurethane Wastes: A Review
}

\author{
Ravindra V. Gadhave*, Shrray Srivastava, Prakash A. Mahanwar, Pradeep T. Gadekar \\ Department of Polymer and Surface Engineering, Institute of Chemical Technology, Mumbai, India \\ Email: ^ra vi.gadha ve3@gmail.com
}

How to cite this paper: Gadhave, R.V., Srivastava, S., Mahanwar, P.A. and Gadekar, P.T. (2019) Recycling and Disposal Methods for Polyurethane Wastes: A Review. Open Journal of Polymer Chemistry, 9, 39-51.

https://doi.org/10.4236/ojpchem.2019.92004

Received: April 11, 2019

Accepted: May 27, 2019

Published: May 30, 2019

Copyright (c) 2019 by author(s) and Scientific Research Publishing Inc. This work is licensed under the Creative Commons Attribution International License (CC BY 4.0).

http://creativecommons.org/licenses/by/4.0/

\begin{abstract}
Polyurethanes (PU) are a general class of polymers prepared by the polyaddition of isocyanates and hydroxyl group containing compounds. PU foams are formed via the reaction of poly-isocyanate and multi-functional hydroxyl compounds resulting in urethane linkages. The foams are formed in wide range of densities and maybe flexible, semi-flexible or rigid in structure. To control the foam structure, blowing agents are employed. These agents are introduced during foam formation through volatilization of low-boiling liquids or through the formation of gas due to chemical reaction. Additionally, surfactants, catalysts, etc. are used during the manufacturing of foams. PU, including PU foams, is one of the most important groups of materials today and hence, their recycling has been of great interest. Many methods of recycling PU are available and many more are being studied further. However, no method has seen large scale commercialization or is brought into regular practice. The objective of this review is to bring to light the various technologies available and their current status of development as well as newer upcoming methods that may be available in the future.
\end{abstract}

\section{Keywords}

Recycling, Polyurethane, Foam, Sustainability, Waste Management

\section{Introduction}

The world polymer and plastic industry has produced about 322 million tons of materials in 2015, including thermoplastics and polyurethanes (PU). China is the largest producer with almost 90 million tons followed by Europe with 58 million tons [1]. The total annual production of PU-based products was nearly 11.5 million tons in the Asia Pacific region and it is projected to be over 15.5 million tons in 2019. PU is one of the most widely used polymer materials be- 
cause of its versatile nature such as cost benefits, energy savings and durability. PU foams may be classified into three types based on their densities: these are flexible, semiflexible, semirigid, and rigid foam. Because of this versatility, PU is widely used for a variety of applications such as furniture, insulation walls, roofs, coatings, adhesives, and automotive parts [2] [3] [4].

PU also generates significant amounts of waste in the various form of which only $29.7 \%$ is recycled, $39.5 \%$ is recovered through energy recovery processes while landfill is unfortunately the first choice in many countries with a $30.8 \%$ of the total waste. The natural slow decay of PU materials and their poor disposal management create a severe hazard to environmental pollution when these materials are dumped after use. As a rough estimate, PU amounts to about $7.7 \%$ of the global plastic demand since is manufactured for building insulation, automotive industry, and insulating foams for fridges. Following the policy toward zero waste plastic and polymer to landfill by 2025 scenario, the inclusion of compounds such as polymer foam wastes as a recycled and reusable material in substitution of varying amounts of aggregates or fine compounds is therefore of great interest in the production of new materials, because of their physical and chemical characteristics, the reduction of other raw materials, and the energy and water savings. In situations where recycling is not the most viable option, energy recovery is the alternative. Generally the combustion process could be wrong, which leads to generate poisonous gas that contribute to the greenhouse effect and pollute the environment [5]. The final use of the recycled materials as coating in facades, interior floor soils, mortar for grouting, coating materials and composite additives is discussed.

The objective of this review is to bring to light the various technologies available and their current status of development as well as newer upcoming methods that may be available in the future. The reader of this paper will be introduced to the sources of PU waste generation and the basic of mechanical, chemical and biodegradation mechanism of PU degradation followed by more in-depth study and overview of the current situation of each route. Brief introductions to some of the applications of the recycled PU waste are also included in the review. Finally, the discussion is shifted towards the newer and more developing technologies and their current state.

\section{PU Wastes}

The recycling of waste PU can be carried out by three major categories such as physical recycling, chemical recycling (chemical degradation), and combined chemolysis. Physical recycling of PU foam waste is simple, cost-effective, convenient, and environmentally friendly. The two most important ways to recycle PU foam wastes are: mechanical/physical recycling and chemical recycling [6]. One of the most effective ways to recycle PU foams is to triturate polymer foams and to integrate them into a new material (Figure 1) [7]. Mechanical recycling covers recycling routes to reuse PU without chemical decomposition. Mechanical 

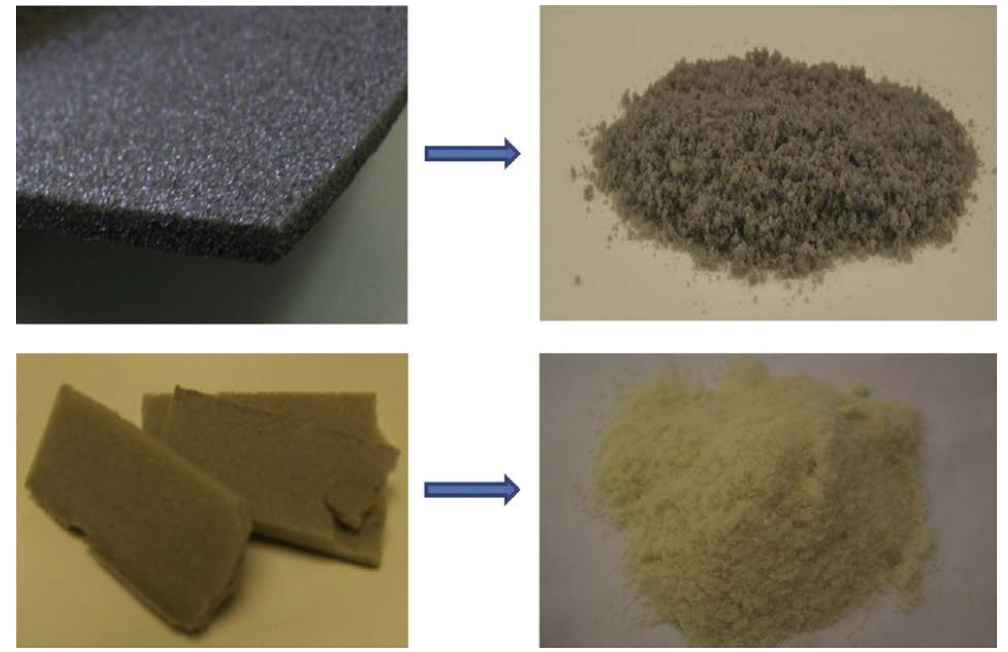

Figure 1. Different PU foam samples after foams. PFW, Polyurethane foam waste mechanical grinding.

recycling reduces the waste into small particles of up to few millimeters in diameter to fine powders. The industry often employs these wastes as inert filler or as a diluent for polyols to produce new PU compound. On the other hand, chemical recycling includes glycolysis, hydrolysis, aminolysis, and thermo chemical and biodegradation processes. PU degradation is achieved by a number of glycolysis reagents and catalysts that are generally found to be expressed under various conditions. In this kind of recycling, the objective is to recover the initial raw materials, especially to produce high-quality recycled monomers of polyol to include in a new polymer of the same nature.

Biodegradation is the action of microorganisms that causes decomposition of polymeric chains into smaller molecules [8]. The natural degradation of polymeric substances is a function of the chemical structure, molecular orientation, crystallinity, and the density of cross-linking, and can be enhanced either by hydrolysis or oxidation reactions from chemical or biochemical origins and involving natural or from other sources [9] [10] [11] [12]. Some references proposed that, along with the fact that different enzymes are capable to biodegrade the medium in a high range of microorganisms; the product of degradation contains mainly the polyol type and the hydrolysis-susceptible ester bonds.

\subsection{Recycled Lightweight PU Plaster Materials}

One of the methods to recycle in a mechanical way is grinding PU foams into powders letting them to be reprocessed as fillers in a novel plaster material Previous studies are based on laboratory results that establish the compatibility of PU with binder based on plaster by combining different amounts of the recycled PU wastes to achieve a new lightweight plaster material with thermal isolating properties [13]. The resource comes from industries as a by-product of the automobile industry or from refrigeration production. The quantity of water needed for an adequate consistency grows with the proportion of added foam. 
This increase in water contributes to the workability time of the plaster, not only increasing it but also improving the time that elapses before the onset of setting. The PU filler loading decreases the density while, the thermal resistance improves proportionally. The reaction to fire of these composites measured with the non combustibility test confirmed that taking only into account the influence of the constituents to fire development, its composition is classified as Euroclasses A2 according to European fire reaction classification of building materials for homogeneous products [14].

\subsection{Recycled Lightweight PU Mortar Materials}

The incorporation of PU waste requires no substantial changes to manufacturing technology, which is its biggest advantage. Based on these premises, the same raw materials that other mortars normally use (cement, additives, and water) with recycled $P U$ with a grain size of $0-6 \mathrm{~mm}$ are used as an aggregate replacing traditional sand, perlite, and vermiculite. The same works also evaluate the durability of these mixtures through various accelerated examinations in agreement with standardized norms. The aging tests employed to assess the toughness of the recycled mortars are salt spray test, sulfur dioxide testing, and hot water resistance to evaluate the hydrolysis of polymer, freeze cycles, and hot dry atmospheres. In all the mentioned cases, even when the durability tests are really aggressive and use for the determination of the robustness of PU boards used in construction and not for plasterboards with less aggressive test, it has been confirmed that the mechanical behavior remained comparative with regard to the reference specimens not subjected to any climatic test [15].

\subsection{Recycled Lightweight PU Asphalt Materials}

The application of various types of waste materials for modification of asphalts has been successfully used in road pavements, obtaining asphalt polymeric composites, sometimes well known and regulated [16] [17] [18] [19]. PU as reactive polymer with functional groups capable to chemically interact with bitumen compounds for obtaining PU modified bitumen [20]. Despite bitumen composition, dimensionally stable bituminous foams can be successfully obtained, even from the softest base [21]. More stable and less deformable bituminous mixtures were obtained with a lower quantity of cavities, which contributes to greater hardness.

\subsection{Eco-Friendly PU Coatings and Adhesives}

PU-based adhesives have good properties as flexibility and durability. These are broadly classified as-

- One-component PU adhesives.

- Two-component PU adhesives.

Recycling option is really interesting for PU foam wastes from scrapped buildings as well but is a complex process due to the use of flame retardants, cat- 
alysts and other additives in these kinds of materials [22] [23] [24]. Different recycling process for PU foam is discussed in Table 1.

\section{Chemical De-Polymerization of Polyurethane Foams}

\subsection{Chemolysis of PU Foam}

Chemical recycling of PU foam is carried out through degradation mechanism in the presence of various degradation reagents. PU foam waste can be gradually de polymerized to form various organic compounds, original reactants, or other

Table 1. Different recycling process for PU foam.

\begin{tabular}{|c|c|c|}
\hline Recycling Process & Description & Process Yield \\
\hline Mechanical recycling & $\begin{array}{l}\text { Covers recycling routes to reuse PU without chemical } \\
\text { decomposition. }\end{array}$ & $\begin{array}{l}\text { The process reduces the waste into small particles of up to } \\
\text { few millimeters in diameter to fine powders which can be } \\
\text { used as inert fillers. }\end{array}$ \\
\hline Chemical recycling & $\begin{array}{l}\text { Chemical recycling includes glycolysis, hydrolysis, } \\
\text { aminolysis, and thermo-chemical and biodegradation } \\
\text { processes. }\end{array}$ & $\begin{array}{l}\text { Chemical recycling is done to recover the initial raw } \\
\text { materials, especially to produce high-quality recycled } \\
\text { monomers of polyol to include in a new polymer. }\end{array}$ \\
\hline Chemolysis & $\begin{array}{l}\text { PU foam waste can be gradually de polymerized to form } \\
\text { various organic compounds, original reactants, or other } \\
\text { low molecular weight oligomers. }\end{array}$ & $\begin{array}{l}\text { The properties of products formed by chemolysis of PU } \\
\text { depend greatly on the type of degradation reagents used } \\
\text { during the chemolysis process. }\end{array}$ \\
\hline Hydrolysis & $\begin{array}{l}\text { Hydrolysis of PU is based on the chemolysis of waste PU } \\
\text { foam with water vapor and alkali metal hydroxide as a } \\
\text { catalyst at high temperature under high pressures. }\end{array}$ & $\begin{array}{l}\text { Hydrolysis of PU foam has many side reactions which are } \\
\text { responsible for undesired by-products such as } \\
\text { 4,4'-diaminodiphenylmethane (MDA), 2,4-toluylene } \\
\text { diamines, and 2,6-toluylene diamines. }\end{array}$ \\
\hline Alcoholysis & $\begin{array}{l}\text { Alcoholysis reaction is carried out using a series of alcohols } \\
\text { and metal hydroxide such as sodium hydroxides or } \\
\text { potassium hydroxides at high temperature under } \\
\text { high pressure. }\end{array}$ & $\begin{array}{l}\text { This process produces the original reactants, i.e., polyols } \\
\text { and urethane products. }\end{array}$ \\
\hline Acidolysis & $\begin{array}{l}\text { Acidolysis reactions were carried out by various types of } \\
\text { inorganic and organic acids. }\end{array}$ & $\begin{array}{l}\text { This process leads to a series of products such as amides, } \\
\text { polyols, amine salts, and oligo ureas. }\end{array}$ \\
\hline Aminolysis & $\begin{array}{l}\text { Aminolysis method was carried out by the amine method } \\
\text { which generally used hydroxyl and amino-derived } \\
\text { compounds. }\end{array}$ & $\begin{array}{l}\text { Aminolysis methods of PU foams generated various } \\
\text { degraded product such as substituted polyol and } \\
\text { polyamines compound. }\end{array}$ \\
\hline Glycolysis & $\begin{array}{l}\text { Glycolysis carried out through trans esterification reaction } \\
\text { by reacting PU foam with various diol compounds at } \\
\text { elevated temperatures. }\end{array}$ & $\begin{array}{l}\text { The main objective of glycolysis of PU foam is the effective } \\
\text { recovery and reuse of polyols. }\end{array}$ \\
\hline Combined Chemolysis & $\begin{array}{l}\text { The combined chemolysis methods comprise multiple } \\
\text { stages and include processing with different chemical } \\
\text { treatment such as hydroglycolysis, glycolysis-aminolysis, } \\
\text { and aminolysis-hydrolysis. }\end{array}$ & $\begin{array}{l}\text { The process not only uses a different chemical agent but } \\
\text { also consists of two or more steps which combine totally } \\
\text { distinct chemical treatment. }\end{array}$ \\
\hline Hydroglycolysis & $\begin{array}{l}\text { PU foam is degraded by a combination of various } \\
\text { chemicals such as water, diethylene glycol, and alkali metal } \\
\text { hydroxides such as lithium hydroxides ( } \mathrm{LiOH}) \text {, } \\
\text { sodium hydroxides, and potassium hydroxides at } \\
\text { elevated temperature. }\end{array}$ & $\begin{array}{l}\text { This process produces higher quality product mixture } \\
\text { against simple glycolysis process. }\end{array}$ \\
\hline Glycolysis-Aminolysis & $\begin{array}{l}\text { The decomposition of PU by ethylene glycol and } \\
\text { ethanolamine mixtures at elevated temperatures. }\end{array}$ & $\begin{array}{l}\text { The resulting product being can be used to produce rigid } \\
\text { PU foams. }\end{array}$ \\
\hline Aminolysis-Hydrolysis & $\begin{array}{l}\text { Chemolysis of PU foam through an aminolytic chain } \\
\text { cleavage followed by hydrolysis. }\end{array}$ & This process yields original polyols and amines. \\
\hline
\end{tabular}


low molecular weight oligomers. The properties of PU products formed by chemolysis of PU depend greatly on the type of degradation reagents used during the chemolysis process.

\subsection{Hydrolysis of PU Foam}

Hydrolysis of PU is based on the chemolysis of waste PU foam with water vapor and alkali metal hydroxide as a catalyst at high temperature $\left(250^{\circ} \mathrm{C}-340^{\circ} \mathrm{C}\right)$ under high pressures as shown in Figure 2.

This chemolysis process formed amines, alcohol, and CO2. Hydrolysis of PU foam has many side reactions which are responsible for undesired by-products such as 4,4'-diaminodiphenylmethane (MDA), 2,4-toluylene diamines, and 2,6-toluylene diamines. Most of these are highly toxic chemicals and affect largely by increasing viscosity of the reaction system.

\subsection{Alcoholysis of PU Foam}

Alcoholysis reaction is carried out using a series of alcohols and metal hydroxide such as sodium hydroxides or potassium hydroxides at high temperature under high pressure. Alcoholysis reaction is a similar process as hydrolysis reactions. This process produces the original reactant, i.e., polyols and urethane products. This process requires oxygen-free environment and high temperatures to degrade PU foam for converting into gas, oil, and solid products.

\subsection{Acidolysis of PU Foam}

Another type of chemolysis reaction which was carried out by many researchers in the recycling of waste is acidolysis of PU foam. Acidolysis reactions were carried out by various types of inorganic and organic acids. The urethane group present in PU foam was decomposed using inorganic acids and formed substituted amine salts and substituted polyol according to the following reactions scheme as shown in Figure 3.

Furthermore, acidolysis reactions are also carried out at moderately low temperatures $\left(60^{\circ} \mathrm{C}\right)$ and atmospheric pressure for short periods of time. This process leads to a series of products such as amides, polyols, amine salts, and oligo ureas.

\subsection{Aminolysis of PU Foam}

Another type of chemolysis reaction in the recycling of PU foam waste is aminolysis. Aminolysis method was carried out by the amine method which generally

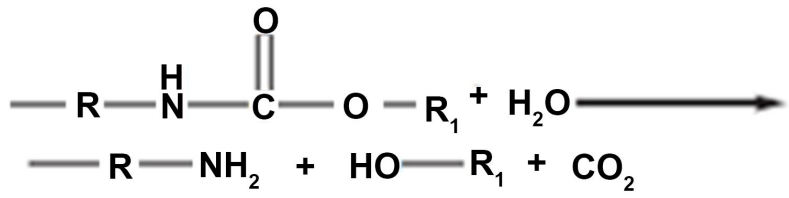

Figure 2. Hydrolysis of PU foam [25]. 


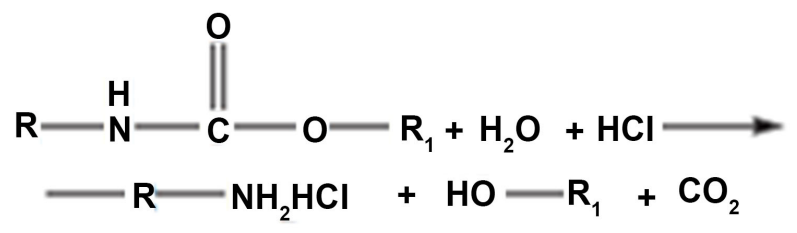

Figure 3. Acidolysis of PU foam [25].

used hydroxyl and amino-derived compounds [26]. Aminolysis methods favor low temperature reaction conditions, and the chemolysis reaction mechanism is similar to the ester exchange process. The decomposed products formed in the study were directly used as a hardener of epoxy resin. Aminolysis methods of PU foams generated various degraded product such as substituted polyol and polyamines compound.

\subsection{Glycolysis of PU Foam}

Glycolysis reaction is the extensively explored chemolysis reaction route for waste PU foam. Glycolysis carried out through trans esterification reaction by reacting $\mathrm{PU}$ foam with various diol compounds at elevated temperatures, preferably above $200^{\circ} \mathrm{C}$ [27]. Glycolysis is achieved in the presence of various catalysts such as tertiary amines, alkaline metal hydroxides, tin, and bismuth-derived organic compounds. The main objective of glycolysis of $\mathrm{PU}$ foam is the effective recovery and reuse of polyols for the manufacture of new PU-based material.

Glycolysis of PU foam is preferred due to the following advantages: 1) requires low temperature, 2) reaction time is comparatively short, and 3) the end-product can be used to further produce virgin PU [28] [29].

Several side chemical reactions on the urethane group of PU foam occur during the chemolysis process. This problem is severe in the presence of supplementary functional groups in the foam. In case of flexible PU foam, urea linkage is of higher percentage, and the maximum percentage of urethane linkage is 35 molar percent. Furthermore, other functional groups such as allophanate and biuret functional groups may also be present. However, these functional groups are labile in nature and break prior to the breaking of the urethane and urea functional groups. These groups, in the presence of other impurities, are mainly responsible for side reactions and undesired products which restrict the widespread use of chemolysis of PU foam. The combined chemolysis methods of PU foam comprise two or more reagents, solvents, and/or different organic chemicals involving different chemical treatment process.

\section{Combined Chemolysis of PU Foam}

Chemolysis of waste PU foam produces multiple undesired products which are difficult to control. A substitute is the separation and purification of the formed polyol, but this is a very costly and time consuming process. The new process not only uses a different chemical agent but also consists of two or more steps 
which combine totally distinct chemical treatment. Combined chemolysis processes have immense potential growth for future industrial applications. The combined chemolysis methods comprise multiple stages and include processing with different chemical treatment such as hydroglycolysis, glycolysis-aminolysis, and aminolysis-hydrolysis.

\subsection{Hydroglycolysis}

PU foam is degraded by a combination of various chemicals such as water, diethylene glycol, and alkali metal hydroxides such as lithium hydroxides ( $\mathrm{LiOH})$, sodium hydroxides, and potassium hydroxides at elevated temperature, i.e., $200^{\circ} \mathrm{C}$. This process is referred to as hydroglycolysis [30] [31] [32] [33] the process is comparatively a complex chemical treatment process which is carried out by adding water to a glycolysis steps. Ford Motor Company established this process; they claimed that this process produces higher quality product mixture against simple glycolysis process. A schematic representation of the hydroglycolysis process is shown in Figure 4 [34].

\subsection{Glycolysis-Aminolysis}

The decomposition of PU by ethylene glycol and ethanolamine mixtures at elevated temperatures (About $200^{\circ} \mathrm{C}$ ) have been previously reported with the resulting product being used to produce rigid PU foams [35] several amine functionality compounds with glycols were also used to break urethanes by employing the use of secondary aliphatic amines such as di-n-butylamine together with one or more glycols. This process runs at elevated temperatures between $180^{\circ} \mathrm{C}$ and $220^{\circ} \mathrm{C}$ so that the splitting of ureas may be curbed.

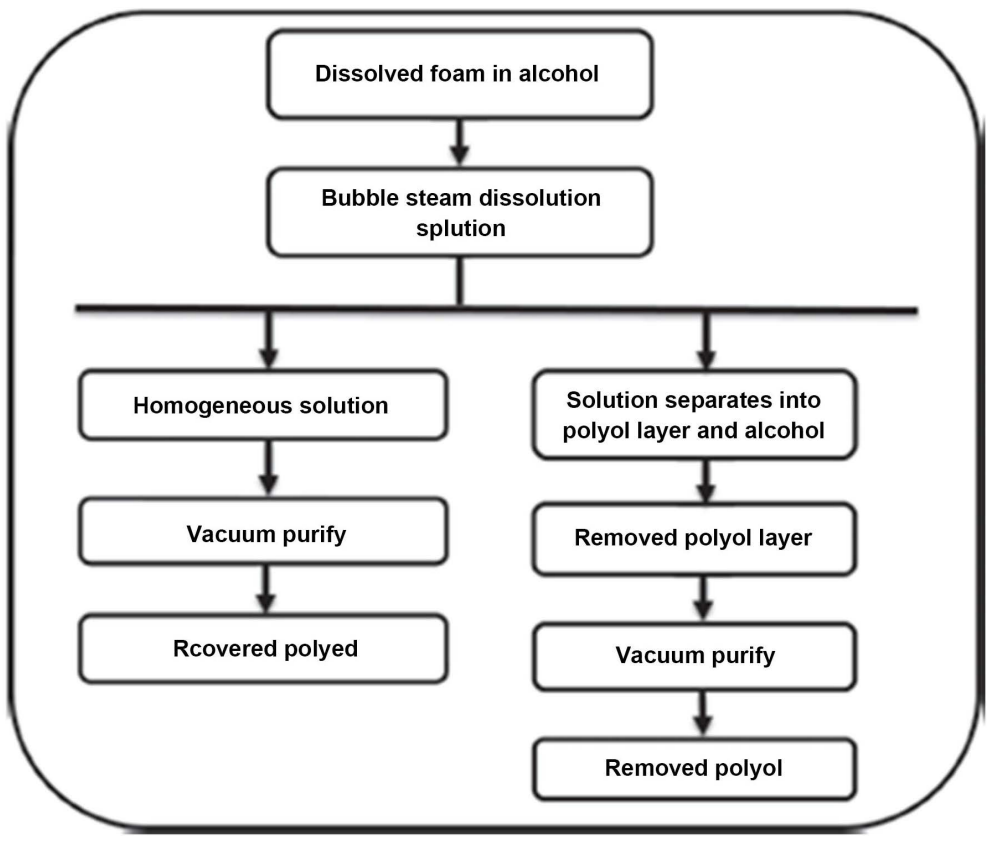

Figure 4. Block diagram of hydroglycolysis recycling method. 


\subsection{Aminolysis-Hydrolysis}

Aminolysis-hydrolysis of PU foam has been scarcely studied so far and there are very few scientific papers concerning the utilization of this process on a commercial scale. Chemolysis of PU foam through an aminolytic chain cleavage followed by hydrolysis yields original polyols and amines. Studies on the combined aminolysis and hydrolysis of PU foam by diethanol amine and aqueous $\mathrm{NaOH}$ solution mixtures have also been conducted [36].

\section{Combined Chemolysis in Comparison to Other Recycling Methods of PU Foams}

An elaborative view of the differences between the products obtained by combined chemolysis with respect to mechanical recycling and conventional chemolysis of PU foam [36] [37] [38]. PU foam can be recycled and reused by three routes: 1) Physical recycling, 2) Chemolysis, and 3) Combined chemolysis. The combined hydroglycolysis method is economical and environmentally superior as it uses less amount of solvent and produces less number of unwanted side-products. In addition, the combined glycolysis-aminolysis process leads to a significant decrease in time for the de-polymerization process as compared to the simpler approaches. However, due to the increased technical difficulty and excessive cost, it is a challenge to achieve large-scale industrialized production. Further research is needed to overcome these difficulties.

\section{Conclusion}

Polyurethanes have become an integral part of the human lifestyle today. Unfortunately, this also means that a lot of PU produced ends up as waste via various streams. Landfill is currently the leading route preferred to dispose of the waste. However, PU isn't readily biodegradable and the presence of various additives, surfactants, blowing agents, catalysts, etc. make it even more difficult to re-process. Recycling of PU wastes is majorly done by three routes-physical, chemical and bio-degradation. Mechanical degradation involves reducing the particle size of the waste into a fine powder and using this powder as a filler or diluent for new PU compounds. The chemical route involves breaking down of the PU backbone and recovering the initial raw materials that can be re-processed into newer polymers of similar nature. Bio-degradation is the degradation of the polymer taking place by the action of micro-organisms which decompose the polymeric chains into smaller molecules. Even though many routes are discussed in this review, PU waste recycling hasn't become a commercial success due to many process limitations and the variety of the material itself. In the current state, none of the recycling options available for PU are able to provide a consistent, high quality, re-usable product. Also, the cost, infrastructure and the low yield are just some of the major hurdles that need to be addressed before any manufacturer can look to recycling as a viable and sustainable solution for recycling PU waste. 


\section{Future Trends}

PU foams are formed in a wide range of densities and maybe flexible, semirigid or rigid in structure. Various blowing agents, additives, surfactants, catalysts, etc. are added during manufacturing of foams. PU, including foams, is one of the most important groups of materials available today and hence, their recycling is of great economical, as well as, environmental interest. In-spite of the various routes available today for PU foam recycling, like landfill, chemical degradation, physical breakdown, etc., none of these routes have been economically successful as a business model. Also, from the environmental point of view, none of the methods are able to produce high quality, re-usable, virgin-like raw materials that can allow foam manufacturers to use the products formed after PU degradation to make new products without compromising on the properties of the final product/foam.

A high conversion yield and high product quality process is required for recycling of $\mathrm{PU}$ foams to be seen as a viable and profitable solution to manage foam waste. The process needs to economical for large businesses to develop interest while also being environmentally important giving high quality raw materials for re-processing.

With increasing environmental awareness and depleting natural sources, recycling is proving to be more than the need of the hour. High conversion, high quality recycling will not only reduced the rate of environmental damage but support in building a sustainable future.

\section{Conflicts of Interest}

The authors declare no conflicts of interest regarding the publication of this paper.

\section{References}

[1] PlasticsEurope (2016) Plastics-The Facts 2016: An Analysis of European Plastics Production, Demand and Waste Data. Brussels, Belgium.

[2] Agrawal, A., Kaur, R. and Walia, R.S. (2017) PU Foam Derived from Renewable Sources: Perspective on Properties Enhancement: An Overview. European Polymer Journal, 95, 255-274. https://doi.org/10.1016/j.eurpolymj.2017.08.022

[3] Brains, P.F. (1969) Polyurethanes Technology. John Wiley \& Sons, Hoboken, NJ.

[4] Hepburn, C. (1992) Polyurethane Elastomers. Elsevier Science, Barking, Essex. https://doi.org/10.1007/978-94-011-2924-4

[5] Zia, K.M., Bhatti, H.N. and Bhatti, I.A. (2007) Methods for Polyurethane and Polyurethane Composites, Recycling and Recovery: A Review. Reactive and Functional Polymers, 67, 675-692. https://doi.org/10.1016/j.reactfunctpolym.2007.05.004

[6] Yanga, W., Dongb, Q., Liu, S., Xie, H., Liu, L. and Li, J. (2012) Recycling and Disposal Methods for Polyurethane Foam Wastes. Procedia Environmental Sciences, 16, 167-175. https://doi.org/10.1016/j.proenv.2012.10.023

[7] Cregut, M., Bedas, M., Durand, M.-J. and Thouand, G. (2013) New Insights into Polyurethane Biodegradation and Realistic Prospects for the Development of a Sus- 
tainable Waste Recycling Process. Biotechnology Advances, 31, 1634-1647. https://doi.org/10.1016/j.biotechadv.2013.08.011

[8] Howard, G.T., Norton, W.N. and Burks, T. (2012) Growth of Acinetobacter generic P7 on Polyurethane and the Purification and Characterization of a Polyurethanase Enzyme. Biodegradation, 23, 561-573. https://doi.org/10.1007/s10532-011-9533-6

[9] Chevali, V. and Kandare, E. (2016) Rigid Biofoam Composites as Eco-Efficient Construction Materials. In: Pacheco-Torgal, F., Ivanov, V., Karak, N. and Jonkers, H., Eds., Biopolymers and Biotech Admixtures for Eco-Efficient Construction Materials, Woodhead Publishing Limited, Cambridge. https://doi.org/10.1016/B978-0-08-100214-8.00013-0

[10] Oprea, S. (2010) Synthesis and Properties of Polyurethane Elastomers with Castor Oil as Crosslinker. Journal of the American Oil Chemists' Society, 87, 313-320. https://doi.org/10.1007/s11746-009-1501-5

[11] Molero, C., de Lucas, A., Romero, F. and Rodríguez, J.F. (2008) Influence of the Use of Recycled Polyols Obtained by Glycolysis on the Preparation and Physical Properties of Flexible Polyurethane. Journal of Applied Polymer Science, 109, 617-626. https://doi.org/10.1002/app.28136

[12] Molero, C., Mitova, V., Troev, K. and Rodríguez, J.F. (2010) Kinetics and Mechanism of the Chemical Degradation of Flexible Polyurethane Foam Wastes with Dimethyl H-Phosphonate with Different Catalysts. Journal of Macromolecular Science, Part A: Pure and Applied Chemistry, 47, 983-990. https://doi.org/10.1080/10601325.2010.506408

[13] Gutiérrez-González, S., Gadea, J., Rodríguez, A., Junco, C. and Calderón, V. (2012) Lightweight Plaster Materials with Enhanced Thermal Properties Made with Polyurethane Foam Wastes. Construction and Building Materials, 28, 653-658. https://doi.org/10.1016/j.conbuildmat.2011.10.055

[14] Alameda, L., Calderón, V., Junco, C., Rodríguez, A., Gadea, J. and GutiérrezGonzález, S. (2016) Characterization of Gypsum Plasterboard with Polyurethane Foam Waste Reinforced with Polypropylene Fibers. Materiales de Construcción, 66, 100. https://doi.org/10.3989/mc.2016.06015

[15] Junco, C., Gadea, J., Rodríguez, A., Gutiérrez-González, S. and Calderón, V. (2012) Durability of Lightweight Masonry Mortars Made with White Recycled Polyurethane Foam. Cement and Concrete Composites, 34, 1174-1179.

https://doi.org/10.1016/j.cemconcomp.2012.07.006

[16] Poulikakos, L.D., Papadaskalopoulou, C., Hofko, B., Gschösser, F., Cannone Falchetto, A., Bueno, M., et al. (2017) Harvesting the Unexplored Potential of European Waste Materials for Road Construction. Resources, Conservation and Recycling, 116, 32-44. https://doi.org/10.1016/j.resconrec.2016.09.008

[17] Huang, Y., Bird, R.N. and Heidrich, O. (2007) A Review of the Use of Recycled Solid Waste Materials in Asphalt Pavements. Resources, Conservation and Recycling, 52, 58-73. https://doi.org/10.1016/j.resconrec.2007.02.002

[18] Yildirim, Y. (2007) Polymer Modified Asphalt Binders. Construction and Building Materials, 21, 66-72. https://doi.org/10.1016/j.conbuildmat.2005.07.007

[19] Bukowski, A. and Grętkiewicz, J. (1982) Polyurethane Synthesis Reactions in Asphalts. Journal of Applied Polymer Science, 27, 1197-1204. https://doi.org/10.1002/app.1982.070270409

[20] Carrera, V., Cuadri, A.A., García-Morales, M. and Partal, P. (2014) Influence of the Prepolymer Weight and Free Isocyanate Content on the Rheology of Polyurethane Modified Bitumens. European Polymer Journal, 57, 151-159. 
https://doi.org/10.1016/j.eurpolymj.2014.05.013

[21] Izquierdo, M.A., Navarro, F.J., Martínez-Boza, F.J. and Gallegos, C. (2012) Bituminous Polyurethane Foams for Building Applications: Influence of Bitumen Hardness. Construction and Building Materials, 30, 706-713. https://doi.org/10.1016/j.conbuildmat.2011.12.088

[22] Ghosh, B., Gogoi, S., Thakur, S. and Karak, N. (2016) Biobased Waterborne Polyurethane/Carbon Dot Nanocomposite as a Surface Coating Material. Progress in Organic Coatings, 90, 324-330. https://doi.org/10.1016/j.porgcoat.2015.10.025

[23] Howard, G.T. (2002) Biodegredation of Polyurethane: A Review. International Biodeterioration \& Biodegradation, 49, 245-252. https://doi.org/10.1016/S0964-8305(02)00051-3

[24] Zia, K.M., Bhatti, H.N. and Bhatti, J.A. (2007) Methods for Polyurethane and Polyurethane Composites, Recycling and Recovery: A Review. Reactive and Functional Polymers, 67, 675-692. https://doi.org/10.1016/j.reactfunctpolym.2007.05.004

[25] Yang, W., Dong, Q., et al. (2012) Recycling and Disposal Methods for Polyurethane Foam Wastes. Procedia Environmental Sciences, 16, 167-175.

https://doi.org/10.1016/j.proenv.2012.10.023

[26] Campbell, G.A. and Meluch, W.C. (1977) Polyurethane Waste Disposal Development: Amine Recovery. Journal of Applied Polymer Science, 21, 581-584. https://doi.org/10.1002/app.1977.070210224

[27] Scheirs, J. (1998) Polymer Recycling. Wiley, New York.

[28] Braslaw, J. and Gerlock, J.L. (1984) Polyurethane Waste Recycling. 2. Polyol Recovery and Purification. Industrial \& Engineering Chemistry Process Design and Development, 23, 552-557. https://doi.org/10.1021/i200026a024

[29] Zhu, P., Cao, Z.-B., Chen, Y., Zhang, X.-J., Qian, G.-R., Chu, Y.-L., et al. (2014) Glycolysis Recycling of Rigid Waste Polyurethane Foam from Refrigerators. Environmental Technology, 35, 2676-2684. https://doi.org/10.1080/09593330.2014.918180

[30] Gadhave, R., Srivastava, S., Mahanwar, P. and Gadekar, P. (2019) Lignin: Renewable Raw Material for Adhesive. Open Journal of Polymer Chemistry, 9, 27-38. https://doi.org/10.4236/ojpchem.2019.92003

[31] Gadhave, R., Mahanwar, P. and Gadekar, P. (2018) Lignin-Polyurethane Based Biodegradable Foam. Open Journal of Polymer Chemistry, 8, 1-10. https://doi.org/10.4236/ojpchem.2018.81001

[32] Ulrich, H., Odinak, A., Tucker, B. and Sayigh, A.A.R. (1978) Recycling of Polyurethane and Polyisocyanurate Foam. Polymer Engineering \& Science, 18, 844-888. https://doi.org/10.1002/pen.760181103

[33] Nikje, M.M.A., Garmarudi, A.B. and Azni, B. (2011) Polyurethane Waste Reduction and Recycling: From Bench to Pilot Scales. Designed Monomers and Polymers, 14, 395-421. https://doi.org/10.1163/138577211X587618

[34] John, L., Gerlock, J.B. and Albright, J. (1982) Process for Polyol Recovery from Polyurethane Foam Comprising Alcohol and Steam Hydrolysis. US Patent No. 4316992.

[35] Kondo, O., Hashimoto, T. and Hasegawa, H.U.S. (1993) Patent 4014809, 197722.

[36] Benes, H., Hajek, M., Horak, Z. and Krulis, Z. (2010) Method of Recycling Waste Polyurethane Foams. US Patent No. EP2183311A2.

[37] Asahi, N., Sakai, K., Kumagai, N., Nakanishi, T., Hata, K., Katoh, S. and Moriyoshi, T. (2004) Methanolysis Investigation of Commercially Available Polyurethane 
Foam. Polymer Degradation and Stability, 86, 147-151.

https://doi.org/10.1016/j.polymdegradstab.2004.04.002

[38] Le Gac, P.Y., Choqueuse, D. and Melot, D. (2013) Description and Modeling of Polyurethane Hydrolysis Used as Thermal Insulation in Oil Offshore Conditions. Polymer Testing, 32, 1588-1593. https://doi.org/10.1016/j.polymertesting.2013.10.009 